\title{
Quantifying Root Deformation Caused by Soil Radial Pressure: A Case Study with Vetiver Grass (Vetiveria zizanioides)
}

\author{
Wan-Gou Liu ${ }^{1{ }^{* *}}$, Jin-Xiang $\mathrm{Liu}^{1 \dagger}$ and Qi-Fu Ma ${ }^{2}$ \\ ${ }^{1}$ Life Science and Technology School, Lingnan Normal University, Zhanjiang, 524048, China \\ ${ }^{2}$ School of Veterinary and Life Sciences, Murdoch University, 90 South Street, Murdoch, WA, 6150, Australia \\ *For correspondence: liuwangou@163.com \\ $\dagger$ The author contributed equally to this work
}

\begin{abstract}
Roots in compacted soil experience both axial resistance and radial pressure. Axial resistance at root apex and radial pressure perpendicularly at root surface cause root deformation i.e., change in root shape. Although the effects of axial resistance are well described in literature, there is a lack of quantitative approach to examine the radial impact. In addition to morphological observation in root cross sections, this study quantified the radial impact of compacted soil on root surface and vascular cylinder by measuring root roundness $(\mathrm{R})$ and flattening $(\mathrm{F})$ of vetiver (Vetiveria zizanioides L.) seedlings. The plants grown in high bulk density soil $\left(1.58 \mathrm{~g} \mathrm{~cm}^{-3}\right)$ exhibited uneven root surface with invaginations, reduced $\mathrm{R}$ and increased $\mathrm{F}$ in root hair zone, compared with plants in low bulk density soil $\left(1.20 \mathrm{~g} \mathrm{~cm}^{-3}\right)$. However, soil compaction had little effect on vascular cylinder in terms of microscopic observation, the $\mathrm{R}$ and $\mathrm{F}$ values. It is concluded that the measurements of root roundness ( $\mathrm{R}$ ) and flattening $(\mathrm{F})$ are consistent with microscopic observations and can be used to quantify root deformation under soil compaction. (C) 2016 Friends Science Publishers
\end{abstract}

Keywords: Radial pressure; Root deformation; Roundness; Flattening; Vetiver grass

\section{Introduction}

Soil compaction is one of the main soil constraints for agriculture. It affects pore size distribution, geometry, gas and water fluxes, and consequently roots growth (Dexter et $a l ., 2008)$. In general, soil compaction decreases large pores and total porosity, and increases fine pores (Reszkowska et al., 2011). Soils with finer pore size will cause excessive mechanical impedance to roots (Lipiec et al., 2012). Soil mechanical impedance in the field often exceeds $2 \mathrm{MPa}$ penetrometer resistance (Bengough et al., 2011), and its effects on root growth are extensively reviewed (Bengough, 2003; Tracy et al., 2011).

In compacted soil, the roots experience both axial and radial pressures (Bengough, 2012). The axial pressure (penetration resistance) on the root apex (tip) causes root deformation such as shorter and thicker roots (Bengough and Mullins, 1990; Materechera et al., 1991; Bengough et al., 2006; Tracy et al., 2012). In contrast, the radial pressure is perpendicularly imposed onto root surface, leading to root bending such as uneven surface (invaginations) (Kolb et al., 2012; Lipiec et al., 2012) and flattened roots (White and Kirkegaard, 2010).

Root deformation under soil compaction can negatively affect the acquisition of nutrients and water by roots, especially in the root-hair zone (Ranathunge et al.,
2003). The effects of axial pressure on root growth were quantitatively reported in many studies by measuring the changes in root elongation (Rosolem et al., 1998; Bengough et al., 2011) and diameter (Bengough et al., 2006) as a fraction of the control. However, the effect of radial pressure on root growth impact still largely depends upon qualitative and arbitrary descriptions, such as root invaginations (Kolb et al., 2012; Lipiec et al., 2012) and flattening (White and Kirkegaard, 2010). In this study, we used a novel approach to quantify the deformation of root shape due to radial pressure in compacted soil.

\section{Materials and Methods}

\section{Soil Columns Preparation}

Topsoil $(0-20 \mathrm{~cm})$ from a rice field in southern China $\left(21^{\circ} 15^{\prime} \mathrm{N}, 110^{\circ} 28^{\prime} \mathrm{E}\right)$ was collected. The sandy loam with soil $\mathrm{pH}$ of 5.8 contained organic matter of $24.1 \mathrm{~g} \mathrm{~kg}^{-1}$, total $\mathrm{N}$ of $1.18 \mathrm{~g} \mathrm{~kg}^{-1}$, available $\mathrm{N}$ of $93.48 \mathrm{mg} \mathrm{kg}^{-1}$, available $\mathrm{P}$ of $89.7 \mathrm{mg} \mathrm{kg}^{-1}$, and available $\mathrm{K}$ of $78.8 \mathrm{mg} \mathrm{kg}^{-1}$. The average soil bulk density of $0-20 \mathrm{~cm}$ depth was $1.20 \mathrm{~g} \mathrm{~cm}^{-3}$. Gravimetric water content of this soil was $19.9 \%$ (w/w). The soil was air dried and passed through a 2-mm sieve, and added with urea at $580 \mathrm{mg} \mathrm{kg}^{-1}$ and $\mathrm{KH}_{2} \mathrm{PO}_{4}$ at $580 \mathrm{mg} / \mathrm{kg}$ of soil. For the convenience of soil potting, soil water

To cite this paper: Liu, W.G., J.X. Liu and Q.F. Ma, 2016. Quantifying root deformation caused by soil radial pressure: a case study with vetiver grass (Vetiveria zizanioides). Int. J. Agric. Biol., 18: 573-576 
content was adjusted to $10 \%(\mathrm{w} / \mathrm{w})$, and allowed to equilibrate overnight prior to potting. Columns (depth 240 $\mathrm{mm}$, diameter $70 \mathrm{~mm}$ ) were uniformly packed to obtain soil bulk densities of $1.20 \mathrm{~g} \mathrm{~cm}^{-3}$ as un-compaction $\left(D_{1.2}\right)$ and $1.58 \mathrm{~g} \mathrm{~cm}^{-3}$ as compaction $\left(\mathrm{D}_{1.58}\right)$. The packing was made at an interval of every $2 \mathrm{~cm}$ layer, and after compacting each layer, the surface was lightly scarified before adding further soil to ensure homogeneous packing (Tracy et al., 2012). Five replicates were prepared for each bulk density, giving a total of 10 columns.

\section{Plant Material and Growth Conditions}

Seeds of a wild ecotype of vetiver grass (Vetiveria zizanioides) from southern China (Xia and Ao, 1998) were collected from the Grass Research Station of Lingnan Normal University $\left(20^{\circ} 55^{\prime} \mathrm{N}, 110^{\circ} 11^{\prime} \mathrm{E}\right)$ and sown in soil in plastic pots $(18 \mathrm{~cm}$ high, $25 \mathrm{~cm}$ in diameter). After germination, uniform vetiver seedlings with four leaves were transplanted into the columns at one plant per column in a naturally lit greenhouse. During the experiment, soils were watered by weighing to gravimetric water content of $13 \%$ (w/w) daily. To minimize evaporation the surface of the soil was covered with a $5 \mathrm{~mm}$ thick layer of perlite. The average minimum and maximum temperatures during the experiment were about 28 and $35^{\circ} \mathrm{C}$, respectively.

\section{Root Sections and Image Analysis}

At the end of growing period 48-day, five nodal root segments from each soil core (roots in the surface of column were excluded) were cut at $20 \mathrm{~mm}$ from the root apex, i.e. the root hair zoon. The sampled root segments were washed carefully with tap water and then distilled water, and stored prior to microscopy in 50\% ethanol to prevent from tissue shrinkage (Atwell, 1990). Freehand cross sections were stained with $1 \%(\mathrm{w} / \mathrm{v})$ safranine. Five complete cross sections of each root were selected randomly and mounted on glass slides for microscopy (Nikon Ys100 microscopy, objective lens, 10×). Photographs were taken with a digital camera (YM310, Yichuang Electronics Ltd. Shangdong, China) and traced using the AOI tool of Image-Pro Plus 6.0 (Media Cybernetics Inc.). The outline of both outer epidermis and pericycle were analyzed to obtain area (A), perimeter $(\mathrm{P})$, maximum diameter $\left(\mathrm{d}_{\max }\right)$ and minimum diameter $\left(\mathrm{d}_{\min }\right)$.

\section{Quantification of Root Shape}

Roundness (R): roundness in geology is the degree of smoothing due to abrasion of sedimentary particles (psephicity). It is expressed as the ratio of the average radius of curvature of the edges or corners to the radius of curvature of the maximum inscribed sphere. Applied in a 2dimentions, roundness is the measure of how closely the shape of an object approaches that of a circle, as determined by the following formula:

$$
\mathrm{R}=\frac{4 \pi \mathrm{A}}{\mathrm{P}^{2}}(0 \leq \mathrm{R} \leq 1)
$$

Where, $\mathrm{A}$ and $\mathrm{P}$ are the area and perimeter of the object, respectively. The value of roundness is equal to 1 for circular objects and $<1$ for other shapes. At the cross section of a root with certain area, the more edges or corners (uneven) it has, the less the roundness becomes.

Flattening $(\mathrm{F})$ : flattening is the measure of compression of a circle along a diameter to form an ellipse as determined by the following formula:

$$
F=\frac{d_{\max }-d_{\min }}{d_{\text {max }}}(0 \leq F \leq 1)
$$

Where, $d_{\max }$ and $d_{\min }$ are maximum and minimum diameters, respectively. The more a circle is compressed, the more flattening the circle becomes. When $\mathrm{F}=0$, i.e. $\mathrm{d}_{\max }=\mathrm{d}_{\min }$, the ellipse is a circle. When $\mathrm{F}=1$, i.e. $\mathrm{d}_{\min }=0$, the ellipse becomes a line segment.

\section{Data Analysis}

The data of all measured variables in response to two bulk densities were subjected to one-way analysis of variance. Treatment differences were determined by Duncan's multiple range test at $P=0.01$ level. Statistical analyses were conducted using SPSS v.18.0 for windows (SPSS Inc., Chicago, IL, USA).

\section{Results}

\section{Microscopic Observation}

The root shape of vetiver at low soil bulk density $(1.20 \mathrm{~g}$ $\mathrm{cm}^{-3}$ ) was closed to circular (Photo 1a). In contrast under compacted soil $\left(1.58 \mathrm{~g} \mathrm{~cm}^{-3}\right)$ it became flattened (Photo $1 \mathrm{~b}$ ). The cross sections of roots in un-compacted soil had a regular outline with the epidermis composed of smaller cells and lots of root hairs, whereas in the compacted soil the epidermal cells and some cortex cells were damaged with the remnants occupying the outside of the root. The roots from the un-compacted soil showed an elaborate cortical region with several layers of regularly arranged cells where aerenchyma evenly distributed, whereas in compacted soil some aerenchyma were squashed and disappeared by showing deep invaginations in cortex, e.g. a wavy outline at cross section. However, the shape of vascular cylinders was unchanged in compacted soil compared with those in uncompacted soil (Fig. 1).

\section{Quantitative Values}

Compared with un-compacted soil $\left(\mathrm{D}_{1.20}\right)$, the roots in compacted soil $\left(\mathrm{D}_{1.58}\right)$ had reduced roundness $(\mathrm{R})$ and increased flattening $(\mathrm{F})(\mathrm{P}<0.01)$ (Table 1), indicating that 
Table 1: Roundness and flattening of transverse section in root hair zone of vetiver seedling

\begin{tabular}{lllll}
\hline Treatment & \multicolumn{2}{c}{ Roundness (R) } & & \multicolumn{2}{c}{ Flattening $(\mathrm{F})$} \\
\cline { 2 - 3 } \cline { 5 - 5 } & Root & Root & Vascular Cylinder \\
\hline $\mathrm{D}_{1.20}$ & $0.968 \pm 0.019 \mathrm{a}$ & $0.981 \pm 0.009 \mathrm{a}$ & $0.099 \pm 0.010 \mathrm{a}$ & $0.100 \pm 0.015 \mathrm{a}$ \\
$\mathrm{D}_{1.58}$ & $0.829 \pm 0.096 \mathrm{~b}$ & $0.972 \pm 0.007 \mathrm{a}$ & $0.247 \pm 0.022 \mathrm{~b}$ & $0.114 \pm 0.010 \mathrm{a}$ \\
\hline
\end{tabular}

Values followed by different letters differ significantly $(\mathrm{P}<0.01)$. Means \pm SD $(\mathrm{n}=125)$

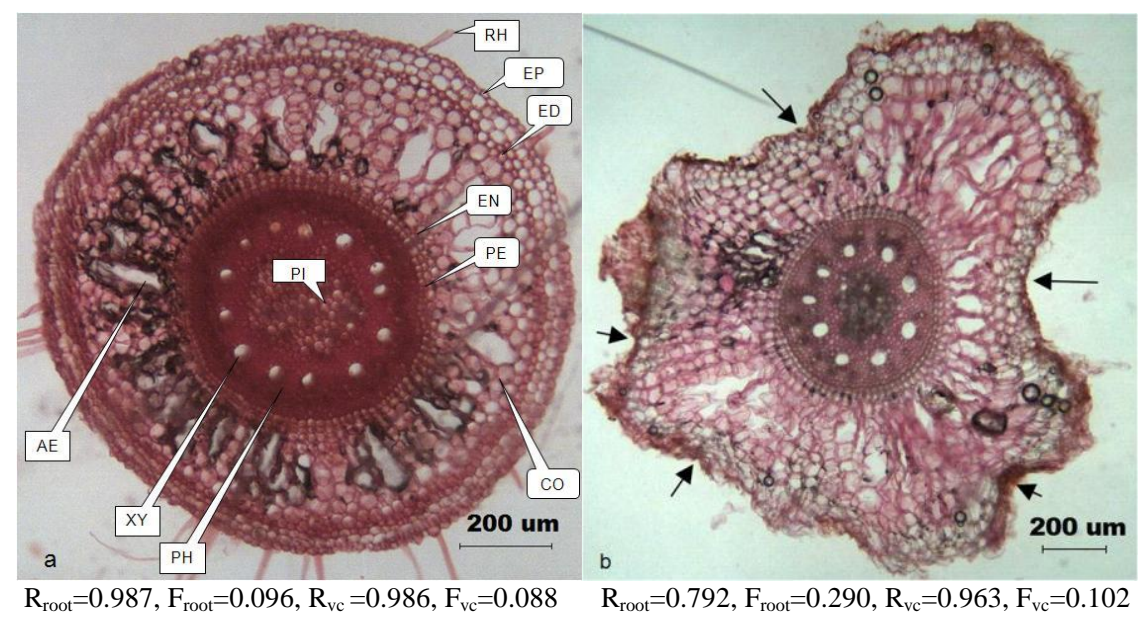

Fig. 1: Cross sectional view of root hair zone of vetiver seedling grown in uncompacted (a) and compacted (b) soils. The values of roundness $(\mathrm{R})$ and flattening $(\mathrm{F})$ of both root and vascular cylinder (vc) are given. Arrows = invaginations in deformed area. RH: root hair, EP: epidermis, EX: exodermis, EN: endodermis, PE: pericycle, CO: cortex, PH: phloem, XY: xylem, AE: aerenchyma, PI: pith

higher soil radial pressure caused uneven root surface and flattened root cylinder. In contrast, neither $\mathrm{R}$ nor $\mathrm{F}$ in vascular cylinder was affected under soil compaction.

\section{Discussion}

Microscopic observations clearly showed that in compacted soil the roots in vetiver had uneven root surface with invaginations and cell deformation in the cortex rather than in vascular cylinder (Fig. 1). The results are consistent with previous findings in Triticum aestivum, Secale cereale and Zea mays that root cell deformation occurred only in cortex (Lipiec et al., 2012). However, in Hordeum vulgare and Triticosecale Wittmack, cell deformation was found in both cortex and vascular cylinder (Lipiec et al., 2012), indicating that root anatomy of different species may have an impact. Besides the difference in root inherent traits, the vetiver roots also has elastic cortex, particularly aerenchyma sandwiched between the soil and vascular cylinder, which would be able to alleviate the radial pressure from soil compaction.

The parameters of roundness $(\mathrm{R})$ and flattening $(\mathrm{F})$ were developed to quantify the deformation of root surface and/or vascular cylinder caused by radical force from soil compaction. Microscopic analysis showed that the higher the soil bulk density, the lower the $\mathrm{R}$ value of root transversal section, indicating more uneven on the root surface. Similarly, the F value of root transversal section increased in compacted soil, i.e. the root had been compressed. However, neither $R$ nor $F$ in vascular cylinder was affected by soil compaction (Table 1). These quantitative measurements are consistent with microscopic observations, indicating $\mathrm{R}$ and $\mathrm{F}$ parameters are useful for quantifying the effect of radial pressure on roots.

In the case of one deep invagination along a root section, however, large $\mathrm{F}$ value can be derived as it is only calculated from $d_{\max }$ and $d_{\min }$. When there are many shallow invaginations in the roots, the $\mathrm{R}$ parameter would give better description of root deformation under soil compaction.

Further study is warranted to minimize the limitation of above parameters because of two dimensional crosssection observations. X-ray computed tomography (CT), which is widely used in the medical sciences, may be applied to acquire cross-sectional image slices of a root segment (Tracy et al., 2011). These image slices can be reconstructed to provide a three-dimensional visualization of the root segment and give its volume $(\mathrm{V})$ and surface area (A). The roundness of a root segment will be:

$$
\mathrm{R}=\frac{4 \pi \mathrm{hV}}{\mathrm{A}^{2}}(0 \leq \mathrm{R} \leq 1)
$$

Where, $\mathrm{h}$ is the length of the root segment. The roundness is equal to 1 for cylinder roots and $<1$ for other shapes. The more uneven in its surface the root is, the less the roundness will become. 
In conclusion, we have presented a novel approach for quantifying root deformation due to radial pressure from soil compaction. The quantitative measurements were consistent with microscopic observations and would be useful for detail evaluation of the relationship between soil compaction and root growth.

\section{Acknowledgements}

This study was supported by China Spark Program (No. 2012GA780012), Key Program of Natural Science Research of Lingnan Normal University (LZL1405) and Zhanjiang key laboratory project of tropical plant resources and development (No. 2014A06008).

\section{References}

Atwell, B., 1990. The effect of soil compaction on wheat during early tillering I. Growth, development and root structure. New Phytol., 115: $29-35$

Bengough, A.G., 2003. Root growth and function in relation to soil structure, composition and strength. In: Root Ecology, Vol. 168, pp: 151-171. Kroon, H.D. and E.J.W. Vissers (eds.). Springer-Verlag, Berlin Heidelberg, Germany

Bengough, A.G, 2012. Root elongation is restricted by axial but not by radial pressures: so what happens in field soil? Plant Soil, 360: 15-18

Bengough, A.G., M.F. Bransby, J. Hans, S.J. McKenna, T.J. Roberts and T.A. Valentine, 2006. Root responses to soil physical conditions; growth dynamics from field to cell. J. Exp. Bot., 57: 437-447

Bengough, A.G, B.M. McKenzie, P.D. Hallett and T.A. Valentine, 2011. Root elongation, water stress, and mechanical impedance: a review of limiting stresses and beneficial root tip traits. J. Exp. Bot., 62: 59-68
Bengough, A.G and C.E. Mullins, 1990. The resistance experienced by roots growing in a pressurised cell. A reappraisal. Plant Soil, 123: 73-82

Dexter, A., E. Czyż, G. Richard and A. Reszkowska, 2008. A user-friendly water retention function that takes account of the textural and structural pore spaces in soil. Geoderma, 143: 243-253

Kolb, E., C. Hartmann and P. Genet, 2012. Radial force development during root growth measured by photoelasticity. Plant Soil, 360: 19-35

Lipiec, J., R. Horn, J. Pietrusiewicz and A. Siczek, 2012. Effects of soil compaction on root elongation and anatomy of different cereal plant species. Soil Till. Res., 121: 74-81

Materechera, S.A., A.R. Dexter and A.M. Alston, 1991. Penetration of very strong soils by seedling roots of different plant species. Plant Soil, 135: $31-41$

Ranathunge, K., E. Steudle and R. Lafitte, 2003. Control of water uptake by rice (Oryza sativa L.): role of the outer part of the root. Planta, 217: 193-205

Reszkowska, A., J. Krümmelbein, L. Gan, S. Peth and R. Horn, 2011. Influence of grazing on soil water and gas fluxes of two Inner Mongolian steppe ecosystems. Soil Till. Res., 111: 180-189

Rosolem, C., M. Schiochet, L. Souza and J. Whitacker, 1998. Root growth and cotton nutrition as affected by liming and soil compaction. Commun. Soil Sci. Plant Anal., 29: 169-177

Tracy, S.R., C.R. Black, J.A. Roberts and S.J. Mooney, 2011. Soil compaction: a review of past and present techniques for investigating effects on root growth. J. Sci. Food Agric., 91: 1528-1537

Tracy, S.R., C.R. Black, J.A. Roberts, C. Sturrock, S. Mairhofer, J. Craigon and S.J. Mooney, 2012. Quantifying the impact of soil compaction on root system architecture in tomato (Solanum lycopersicum) by Xray micro-computed tomography. Ann. Bot., 110: 511-519

White, R.G. and J.A. Kirkegaard, 2010. The distribution and abundance of wheat roots in a dense, structured subsoil-implications for water uptake. Plant Cell Environ., 33: 133-148

Xia, H.P. and D.X. Ao, 1998. Wild vetiver grass distributed in China and its protection and taxonomic problems. Chin. Biodiversity, 6: 292-297

(Received 25 June 2015; Accepted 11 December 2015) 